\section{Intraparotid Tuberculosis Misdiagnosed as Neoplasm on FNAC}

Tuberculosis (TB) is a chronic granulomatous disease caused by Mycobacterium tuberculosis. According to the World Health Organization (WHO), the estimated incidence of TB is 9.4 million and prevalence is 11.1 million cases globally. ${ }^{1}$ TB can involve any organ of human body; lungs, however, are most commonly involved. Extra-pulmonary TB accounts for approximately $20 \%$ of active TB and involves bones, lymph nodes, kidneys, adrenal glands, pericardium, peritoneum and salivary glands. ${ }^{1}$ Parotid gland involvement is rare even in endemic areas of TB. ${ }^{2}$ The diagnosis of parotid gland TB is challenging for the clinicians, as many presenting features of parotid TB mimic various parotid tumors. ${ }^{3}$

We present a case of 44-year lady with history of slowly progressive painless swelling over the left parotid region for 4 months. There were no other associated symptoms such as fever, weight loss, etc. She had no comorbids. On examination, there was a $3 \times 2 \mathrm{~cm}$ firm, non-tender swelling over left parotid region. Overlying skin was normal and swelling was firmly attached to the underlying structures. Facial nerve was intact. The oral cavity and systemic examination were unremarkable.

On ultrasound, there were two small cystic lesions within the parotid parenchyma with few small lymph nodes around the gland. Fine needle aspiration cytology (FNAC) showed few atypical cells and the possibility of salivary gland neoplasm could not be ruled out. Patient subsequently underwent left superficial parotidectomy with level II and III neck dissection. Histopathology revealed granuloma formation composed of palisading epitheloid histiocytes surrounded by lymphocytes and containing multinucleated Langhan's type giant cells with areas of caseation necrosis and no evidence of malignancy (Figures 1 and 2). Diagnosis of TB was made given the histological findings. The patient was referred to infectious disease specialist for further treatment, where she was started on anti-tuberculous therapy (ATT).

TB of the parotid gland is rare, with atypical clinical presentations. It must always be kept in mind as a differential diagnosis in any parotid swelling, especially in endemic countries. FNAC of benign tumors of parotid gland has good sensitivity and specificity (96\% \& 98\%, respectively); whereas, for malignant tumors of parotid gland, the sensitivity and specificity are lower, at $79 \%$ and $96 \%$, respectively. 4

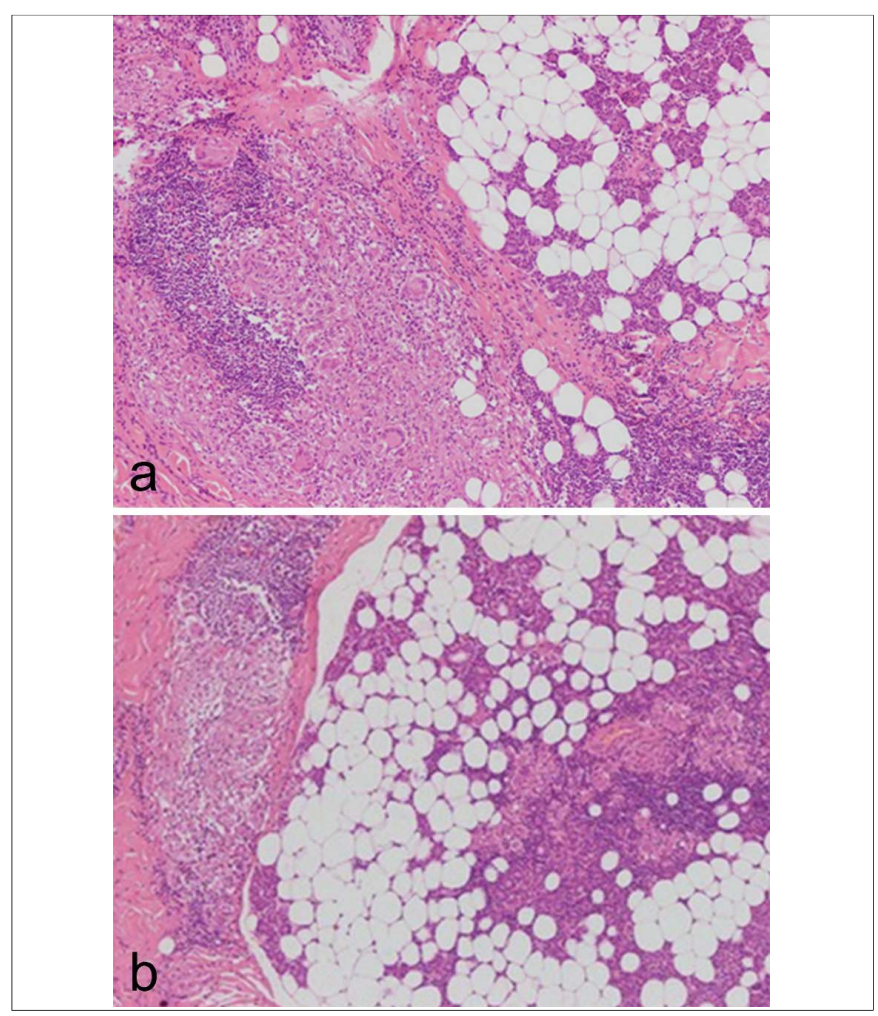

Figure $1(a, b)$ : Chronic granulomatous inflammation involving the salivary gland. These images show granulomas on the left and salivary gland on the right.

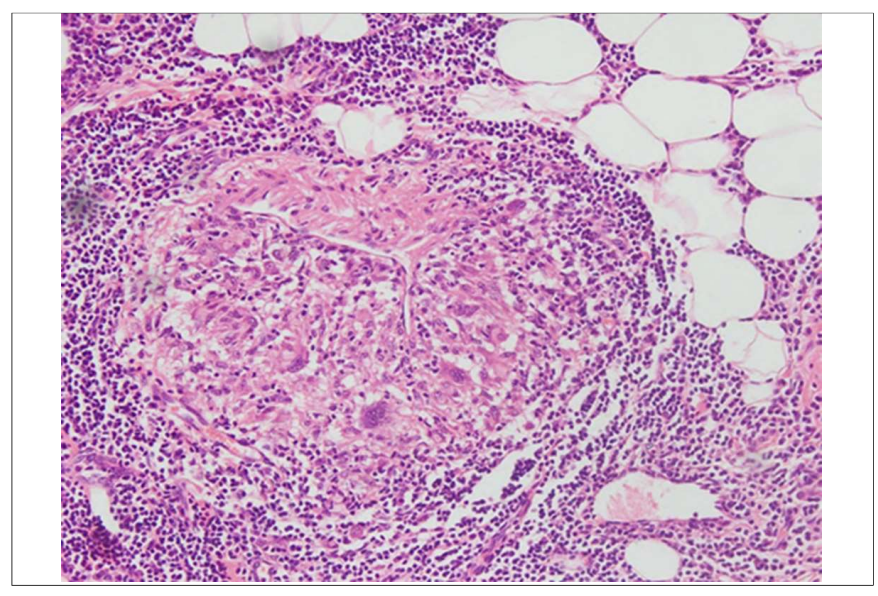

Figure 2: High power view of a granuloma composed of epithelioid histiocytes, surrounded by lymphocytes and interspersed multinucleated giant cells.

All attempts should be made for early diagnosis of tubercular parotitis by FNAC, as the condition can be treated completely by medical management alone.

This case highlights the need for keeping TB in the differential diagnosis of slowly progressive painless swellings of the parotid gland.

\section{REFERENCES}

1. Babazade $\mathrm{F}$, Mortazavi $\mathrm{H}$, Jalalian $\mathrm{H}$. Parotid tuberculosis: A forgotten suspicion (a case report and literature review). Int J Dermatol 2012; 51:588-91. 
2. Sethi A, Sareen D, Sabherwal A, Malhotra V. Primary parotid tuberculosis: Varied clinical presentations. Oral Dis 2006; 12:213-5.

3. Sinha R, Venkatnarayan K, Gupta V, Sood A. A rare case of parotid tuberculosis masquerading parotitis. Int J Med Pediatr Onc 2017: 3:139-40.

4. Kuan EC, Clair JM, John MA. Evaluation of parotid lesions. Otolaryngol Clin North Am 2016; 49:313-25.
Tahir Muhammad, Haissan Iftikhar and Mubasher Ikram

Department of Surgery, The Aga Khan University Hospital, Karachi, Pakistan

Correspondence: Dr. Haissan Iftikhar, Department of Surgery,

The Aga Khan University Hospital, Karachi, Pakistan

E-mail: haissaniftikhar@gmail.com

Received: April 30, 2018; Accepted: January 01, 2019

$\cdots \cdot \hat{n} \cdot \ldots$ 